\title{
Status of Raso Lark Alauda razae in 2003, with further notes on sex ratio, behaviour and conservation
}

\author{
PAUL F. DONALD, M. DE L. BROOKE, MARK R. BOLTON, ROY TAYLOR,
} COLIN E. WELLS, TIM MARLOW and SABINE M. HILLE

\section{Summary}

The global population of the Critically Endangered Raso Lark Alauda razae was estimated in January 2003 at $93-103$ birds and in November 2003 at $76-87$ birds. Of these, only $25-35 \%$ were females. Counts were based on observations of individually colour-ringed and measured birds. Birds were not breeding during the January visit, and were concentrated in two small areas at opposite ends of the island of Raso. This distribution differed substantially from that recorded previously during the breeding season. Three different feeding strategies were apparent: flocking, aggregating around key resources and feeding singly or in pairs. Birds moving to new feeding areas immediately adopted the feeding strategy of other birds present. Birds were seen drinking seawater on several occasions. In November 2003, birds were breeding but nest survival was extremely low due to high rates of egg predation. No evidence was detected of introduced predators on Raso. However, a population of feral cats was found on nearby Santa Luzia, prohibiting natural colonization or deliberate introduction of Raso Lark to the island, despite much apparently suitable habitat there. Faecal analyses showed that these cats feed largely on skinks. Increased tourism development on neighbouring islands is identified as a potential threat to the species.

\section{Introduction}

Raso Lark Alauda razae is listed by the IUCN as Critically Endangered due to its small and fluctuating population and small range (BirdLife International 2000). The species is found only on the uninhabited island of Raso $\left(7 \mathrm{~km}^{2}\right)$ in the Cape Verde Islands, although its ancestors may have arrived in Cape Verde before or at the time that Raso was joined to other neighbouring islands during periods of lower sea level (Hazevoet 1995). The current range on Raso may therefore be a relic of a formerly larger range, though unconfirmed reports of sub-fossil Raso Lark bones being discovered on nearby São Vicente (M. da Ponte Machado pers. comm.) require critical investigation.

Recent studies of the species suggest that the population fluctuates in response to rainfall, and that after long droughts numbers can fall to 10 or fewer pairs (Donald et al. 2003). The population in October 2001 was estimated at 128-138 birds, with what was thought to be a strongly male-biased sex ratio, although this assumption was based on field assessments of sex that might not always have been correct. Nesting was observed following rain in October 2001, but nest predation rates were found to be extremely high, eggs probably being predated by the near-endemic 
Cape Verde Giant Gecko Tarentola gigas (Donald et al. 2003). In December 2002, January 2003 and November 2003, visits were made to Raso to undertake further research on the species, particularly with regard to distribution and ecology during the non-breeding season, and to establish a colour-ringed population. This paper presents results of counts, distribution and estimates of the sex ratio in 2003 based on observations of colour-ringed birds, identifies potential threats to the species and discusses options for the species' conservation.

\section{Methods}

Visits were made to Raso on 4-14 December 2002, 8-17 and 20-23 January 2003, and 4-18 November 2003. In total, 65 birds were caught, measured and fitted with rings: 57 in December 2002, one in January 2003 and seven (plus five retraps) in November 2003. Birds were caught using mist-nets, often with bait of food or water, and fitted with one metal ring and a unique combination of three plastic colour rings. Biometric measurements were taken, including wing and tarsus lengths, weight, and the length, depth and width of the bill.

The population in January 2003 was assessed by adding the known number of colour-ringed birds (58) to estimates of the number of unringed birds. The latter was estimated by plotting the location of unringed birds using portable GPS and using simultaneous counts to reduce the risks of double counting. The population estimate in November 2003 used the same mark-resighting method, and was calibrated by applying the known survival rate of ringed birds to the estimated population in January 2003. The sex ratio was estimated from biometrics of individually measured birds. However, this might have been biased by differences between the sexes in capture rate, for example through females being more wary of people than males. A second estimate of sex ratio therefore added counts of known-sex ringed birds to field assessments of the sex of unringed birds, based primarily on size, bill size and shape, and behaviour (Donald et al. 2003). These were undertaken by observers familiar with the species from previous visits.

Movements of individually marked birds were recorded by plotting the location of each colour-ringed bird using portable GPS each time it was observed. Use by birds of different parts of the island was assessed by plotting all GPS locations $(n=476)$ of individually marked birds on a map grid of $200 \times 200 \mathrm{~m}$.

\section{Results}

\section{Population and sex ratio}

Biometrics clearly separated males from females (Fig. 1), with no overlap in wing or bill length. Based on biometrics, the 65 ringed birds comprised 17 females and 48 males, a highly significant deviation from parity (Binomial test, $P<0.001$ ).

Population estimates carried out in January 2003 were based upon simultaneous counts of unringed birds and adding estimates to the 58 birds that were colour-ringed at that time. A small number of unringed birds were consistently recorded in the same areas of the gravel plain; the rest were in the two main concentrations of birds in the south-west and east of the island (see below). Simultaneous counts of all three subpopulations yielded a consistent estimate of around $40( \pm 5)$ unringed birds. The 


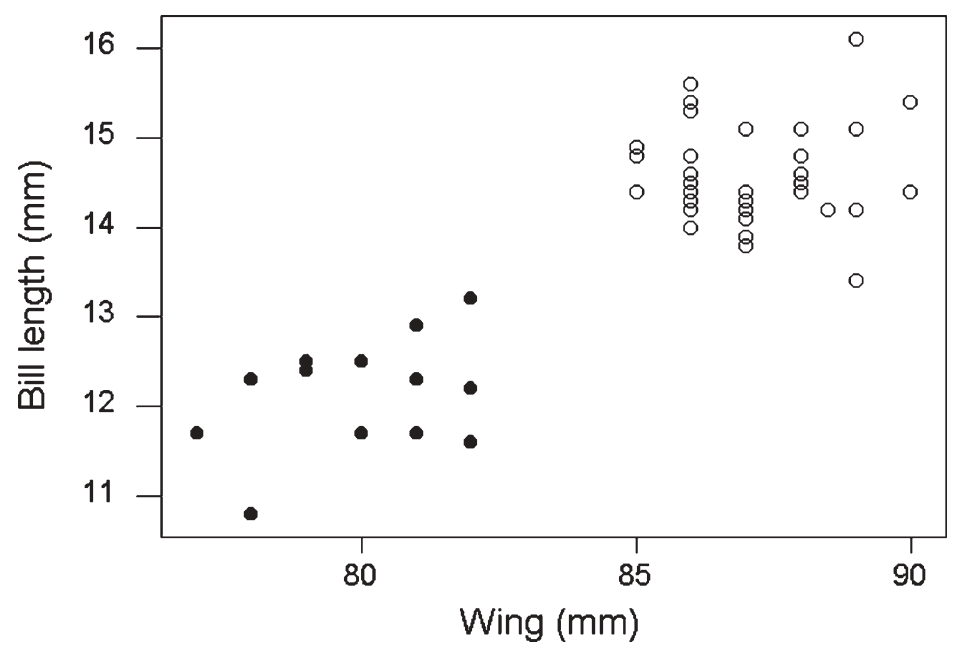

Figure 1 . Wing and bill lengths of male (open circles, $n=42$ ) and female (filled circles, $n=14$ ) Raso Larks caught in December 2002.

inferred population was therefore $98( \pm 5)$ birds, of which $58(60 \%)$ were colourringed. Extrapolating the sex ratio in the colour-ringed population to the population estimate of 98 birds would suggest that the population contained 25 females and 73 males. However, observations in the field suggested a higher proportion of the unringed birds were females than was the case in the ringed population, and therefore that the extrapolated estimate of 25 females was too low. This may have arisen through some systematic difference in the ease with which the different sexes could be caught, possibly through unpaired males congregating in areas where they were easier to trap. Simultaneous counts of unringed birds suggested that 15 were females (based on size, structure and behaviour). The final estimate of the population in January 2003 was therefore 68 males and 30 females, a statistically significant departure from parity (Binomial test, $P<0.01$ ).

All 57 birds ringed in early December 2002 were still alive in late January 2003, representing approximately 75 bird-months without mortality. This suggests that survival rates are very high for such a small passerine.

In November 2003, the population was estimated in two ways. Survival estimates derived from colour-ringed birds were applied to the total population estimate of 98 from January 2003 to give an estimate of 76 . A second estimate was derived by estimating the ratio of ringed to unringed birds and multiplying this by the known number of ringed individuals. This produced an estimate of 87 birds.

\section{Distribution, breeding and feeding}

Birds were not breeding at the time of the visits in December 2002 and January 2003, probably because little rain had fallen in the previous months. Far less green vegetation was present on the island than during breeding in October 2001. The distribution of birds during the non-breeding season was very different to that recorded during breeding in October 2001 (Donald et al. 2003). Two major concentrations, each of 


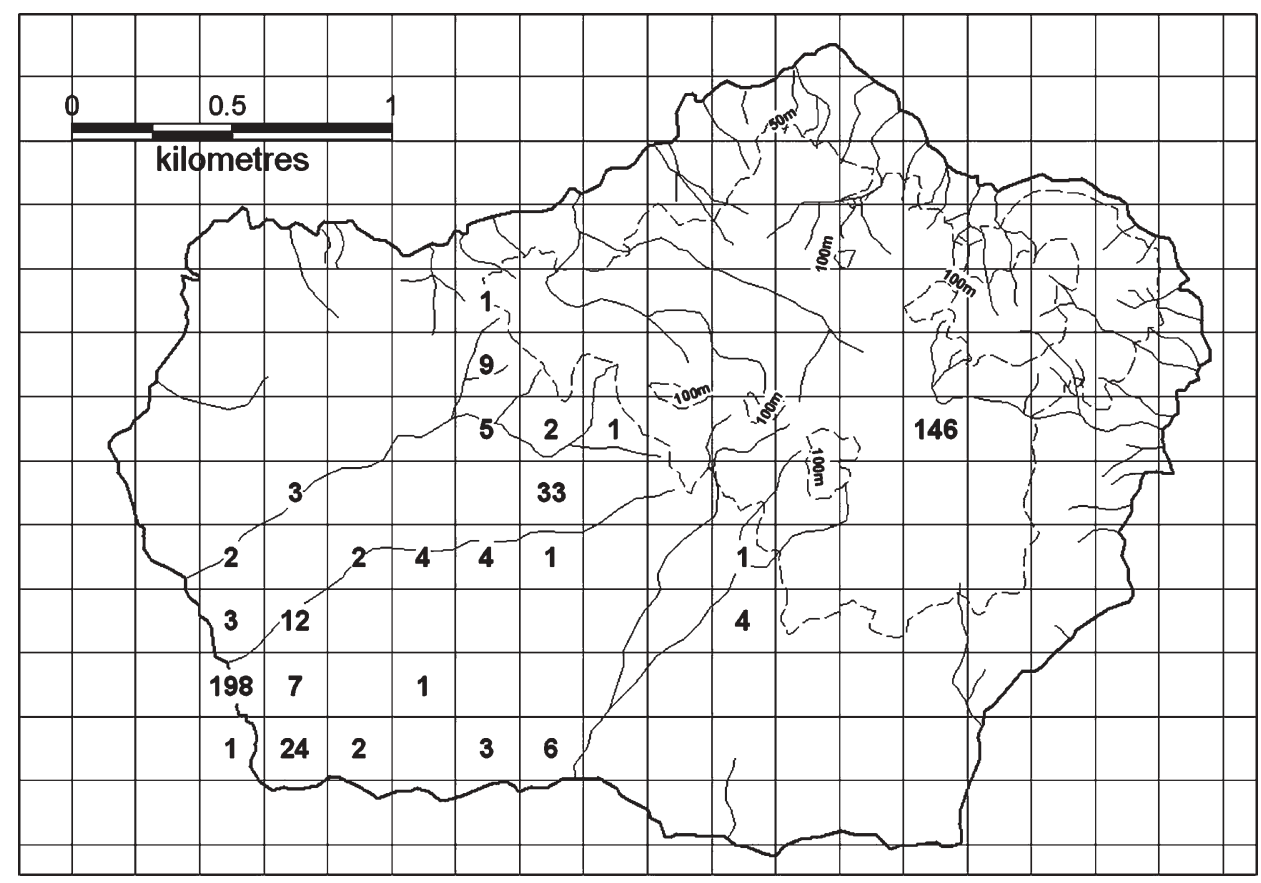

Figure 2. Distribution of Raso Lark in January 2003. Numbers in the $200 \mathrm{~m}^{2}$ cells indicate the total number of observations of all individually ringed birds, and so provide an approximate relative measure of the extent to which each cell was used. Approximately the same numbers of observations of each colour-ringed individual were recorded. Continuous lines indicate dry streambeds, dashed lines the $50 \mathrm{~m}$ and $100 \mathrm{~m}$ contours.

between 30 and 45 birds, were present throughout December 2002 and January 2003 (Fig. 2). The first was around Ponte de Casa in the south-western corner of the island, an area much used during the breeding season because it is sandy and well vegetated. The second was found in a steep-sided gravel valley at the eastern end of the island, the Ribeiro do Ladrão, an area not occupied during breeding in October 2001 or November 2003. In this area, though not in the first, birds were concentrated in a single cohesive and compact flock of up to 45 birds, taking flight and landing together. They were far less approachable than birds elsewhere on the island. This behaviour might have been prompted by the presence of Neglected Kestrels Falco (tinnunculus) neglectus and a Short-eared Owl Asio flammeus in the area. A smaller, and far more approachable, concentration of up to nine birds was present on the southern slopes of Monte de Selada and the rest of the birds were scattered in twos and threes across the gravel plain that makes up around half of Raso's total area. At least three different feeding strategies were therefore in evidence: (I) concentrating around key resources; (2) forming tight mobile flocks and (3) feeding singly or in pairs away from other birds. Individual birds moving between sites adopted the feeding strategy of the other birds there, suggesting that benefits accrue from adopting different strategies on different parts of the island. More detailed analyses of feeding methods will be described elsewhere. 
Drinking of seawater by passerines has rarely been recorded, but appears to be regular behaviour in Raso Lark. On several occasions, birds were seen to fly down to the base of the low cliffs along the islands southern shore and drink from the surface of rock pools (in which, perhaps, the more saline water had sunk to the bottom). This behaviour might be associated more with salt than with water intake.

Although birds were not breeding in January 2003, a single large fledged juvenile (probably a male) was present in the mobile flock in the east of the island, indicating breeding in December 2002. As no rain had fallen in the previous month, this suggested that some birds are capable of breeding in the absence of rain. This bird was easily distinguished from the adults not only in being heavily scaled on the crown and mantle but also in being rufous in plumage tones, particularly on the ear coverts and rump. This was the only juvenile bird in the population.

In November 2003, birds were observed breeding, probably the first full breeding since the autumn of 2001 (cf. Donald et al. 2003). A total of 13 nests built by eight pairs was found. As in October 2001, nest predation rates appeared extremely high. Two nests were found shortly after being predated, and of the remainder, all but one had been predated by the time researchers left the island. All but one were predated at the egg stage; the exception survived to hatch but the chicks were predated at around 3 days old. The same pattern of predation was observed as in October 2001, predated nests containing eggshell fragments in an undisturbed nest lining. As before, the Cape Verde Giant Gecko was considered the most likely nest predator. One nest badly damaged during predation may have been the victim of Brown-necked Ravens Corvus ruficollis. Clutch sizes were smaller than those recorded in October 2001 (Donald et al. 2003), with no clutches exceeding two eggs. Nests were built under Zygophyllum simplex $(n=6)$ or under grass with scattered stems of Abutilon $(n=7)$. A far higher proportion of nests were built under the latter vegetation type than in 2001, when virtually all nests were under Zygophyllum, possibly reflecting differences in the relative abundance of the two plants.

\section{Movements}

Movements of individual birds were examined by plotting GPS locations of each colour-ringed individual. Each individual's location was recorded an average of five times. The maximum distance between plotted locations of each individual was used as an estimate of how mobile the birds were. This showed that the majority of birds were sedentary, but that a small proportion regularly moved between the two main populations in the south-west and east of the island (Fig. 3). Males and females were equally likely to move between different parts of the island and were equally mobile.

\section{Suitability of other islands}

A 3-day visit was made in January 2003 to Santa Luzia, an island of $35 \mathrm{~km}^{2}$ around $16 \mathrm{~km}$ north-west of Raso, to assess the possibility of establishing a second population of Raso Larks there. This island once supported a small human population but was abandoned during the 1960s. Large areas of habitat superficially very similar to that used by Raso Larks were found on the island, although the lack of rain in the months preceding the visit meant that it was not possible to assess the exact extent or types of 


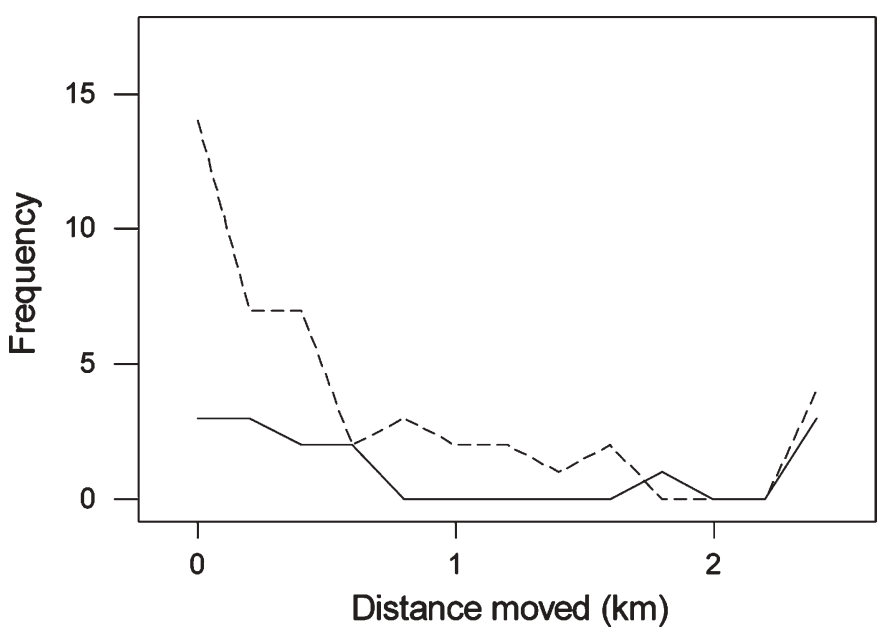

Figure 3. Distribution of maximum recorded movements of colour-ringed birds, shown separately for males (dashed line) and females (continuous line). The longest distances relate to movements between the two main centres of population shown in Fig. 2. After controlling for the number of observations of each individual, there was no significant difference between sexes in the maximum distance moved $\left(F_{1,56}=0.84, P>0.05\right)$.

vegetation present. There was found to be a substantial population of feral cats on the island. Prints and droppings were found on all parts of the island visited, which included most areas below $50 \mathrm{~m}$. Two cats were seen, one of which was a young animal, indicating recent breeding.

Cat faecal samples were collected on Santa Luzia to ascertain their diet from examination of bones. Of 38 samples analysed, 29 contained only the bones of skinks Mabuya, six contained only the bones of mice Mus, one contained only unidentified seabird bones, one contained bones of skinks and an unidentified songbird, and one the bones of skinks and remains of a grasshopper (Orthoptera). Skinks on Santa Luzia were noticeably smaller on average than on islands without cats, such as Raso. Although their bones were present in cat faeces, no mice were seen (although previous visitors describe seeing large numbers; C. Hazevoet pers. comm.). Very few birds of any species were present on the island, the exceptions being a population of around 200 Iago Sparrow Passer iagoensis and nine pairs of Osprey Pandion haliaetus. No Raso Larks were seen on the island, but a number of holes extremely similar to those dug by the species on Raso were found. Whether these were excavated by other visiting passerines or whether Raso Larks occasionally cross to Santa Luzia (which is clearly visible from Raso, although in a direction perpendicular to the prevailing wind) is unclear. A visit to Branco, an island of less than $4 \mathrm{~km}^{2}$ that lies between Santa Luzia and Raso, confirmed that the area of potentially suitable habitat on that island is small or non-existent.

\section{Discussion}

Empirical observations confirm previous assertions (Donald et al. 2003) that the sex ratio of Raso Lark is heavily male-dominated. The reasons for this are unknown, but may be related to differences in bill structure and feeding methods (Donald et al. 
2003). The smaller-billed females spend less time digging than the males and so might have reduced access to certain important food reserves. It is not known whether the strong bias in the sex ratio is a recent phenomenon, though analysis of museum specimens suggests it has not always been present. Of the 45 skins in museums in London, Paris, Lisbon and New York, collected between 1897 and 1970, the ratio of females to males is 19:26, a ratio that does not differ significantly from parity (Binomial test with normal approximation, $P>0.05$ ). The mechanisms driving sex ratios in this species need to be determined if the threat of functional extinction through the extinction of one sex is to be assessed. Future visits to the island should involve separate counts of both sexes, rather than counts of total individual birds as has generally been done previously.

In 2003, the population of Raso Lark was within recorded historical limits of between 10 and around 100 pairs (Ratcliffe et al. 1999, Donald et al. 2003) and there was no evidence of any unusual factors affecting the species. Mammalian predators were absent and there was no evidence of deliberate persecution or of habitat disturbance. High rates of nest predation may be sustainable, as Raso Lark and Giant Gecko have been sympatric for millennia, though trends in nest predation rates are unknown. At present, therefore, the species' main threats are the relatively intractable ones of climate change and extreme natural events. Although desertification has been cited as a threat, droughts have been recorded in Cape Verde throughout the islands' history, and Raso has certainly been arid for at least the last century (Greer 1976), and probably throughout its period of human occupation of around 500 years. There is no evidence that goats have ever been introduced to Raso, an indication that it has always lacked sufficient vegetation for even these hardy grazers (C. Hazevoet pers. comm.). However, a number of more immediate potential threats exist, of which the introduction of mammalian predators and disturbance and nest loss through human visitors remain the greatest. Cats have been present on the island in the recent past, probably ill or unwanted animals deliberately released by local fishermen, although how many animals were involved and whether a breeding population was ever established is unknown. Frequent visits by fishermen from São Vicente and Santo Antão mean that re-introduction of cats or the introduction of other mammals remains a possibility. A second potential threat to the survival of Raso Lark is rapid tourist development on the neighbouring islands of São Vicente and São Nicolau. In 2003, a 200-bed hotel was under construction in Tarrafal, São Nicolau, in clear view of Raso, and there are proposals for tourist development on nearby Santa Luzia. Local fishermen confirmed in 2003 that the number of tourists visiting Raso has increased sharply. The area immediately adjacent to the usual landing point on the island holds one of the highest concentrations of Raso Lark during both breeding and non-breeding seasons (Fig. 2), and the potential for habitat disturbance is high. In particular, the burrows excavated by birds to extract the bulbs of Cyperus bulbosus (Donald et al. 2003) collapse easily when trodden upon. The potential also exists for increased and unregulated tourism to impinge on Raso Lark in other ways, through the accidental introduction of plants, animals or disease, by altering numbers of Giant Geckoes and other potential nest predators (for example by leaving food on the island), by accidental nest damage and by deliberate persecution. The island is a protected area requiring official permission to visit, but this is rarely sought and visitors are essentially unregulated. Island and species management plans need to be prepared and implemented to ensure the long-term survival of Raso Lark and the island's other threatened fauna. 


\section{Acknowledgements}

We are extremely grateful to the following for help in various ways: José Pedro Tavares, Paul Britten, Cornelis Hazevoet, Nigel Butcher, Colin Gooch, Marta de Ponte Machado, Antonio Silva, the staff of the Pensão Residential Jardim, the crew of the Iseric, Orlando Brito and the other fishermen on Raso and Branco. We are most grateful to Julian Francis for generously continuing to support work on Raso Lark. This paper was improved by comments from Cornelis Hazevoet and the editor.

\section{References}

BirdLife International (200o) Threatened birds of the world. Barcelona and Cambridge, U.K.: Lynx Edicions and BirdLife International.

Donald, P. F., de Ponte, M., Pitta Groz, M. J. and Taylor, R. (2003) Status, ecology, behaviour and conservation of Raso Lark Alauda razae. Bird Conserv. Int. 13: 13-28.

Greer, A. E. (1976) On the evolution of the giant Cape Verde scincid lizard Macroscincus coctei. J. Nat. Hist. 10: 691-712.

Hazevoet, C. J. (1995) The birds of the Cape Verde Islands. BOU Checklist No. 13. Tring, U.K.: BOU.

Ratcliffe, N., Monteiro, L. R. and Hazevoet, C. J. (1999) Status of Raso Lark Alauda razae with notes on threats and foraging behaviour. Bird Conserv. Int. 9: 43-46.

PAUL F. DONALD, MARK R. BOLTON

Royal Society for the Protection of Birds, The Lodge, Sandy, Bedfordshire SG19 2DL, U.K.

M. de L. BROOKE

Department of Zoology, University of Cambridge, Downing Street, Cambridge CB2 3 EJ, U.K.

ROY TAYLOR, COLIN E. WELLS

Royal Society for the Protection of Birds, Westleigh Mews, Wakefield Road, Denby Dale, Huddersfield, West Yorkshire HD8 8QD, U.K.

TIM MARLOW

8 Essen Lane, Kilsby, nr Rugby, Warwickshire CV23 8XQ, U.K.

SABINE M. HILLE

Konrad Lorenz Institute for Comparative Ethology, Savoyenstrasse 1a, 1160 Vienna, Austria

Received 22 March 2004; revision accepted 3 November 2004. 